Relations industrielles

Industrial Relations

\title{
The Naked Manager, by E. Dichter, Toronto, Macmillan of Canada, 1974, XII, 156 pp.
}

\section{Alain Larocque}

Volume 30, numéro 3, 1975

URI : https://id.erudit.org/iderudit/028646ar

DOI : https://doi.org/10.7202/028646ar

Aller au sommaire du numéro

Éditeur(s)

Département des relations industrielles de l'Université Laval

ISSN

0034-379X (imprimé)

1703-8138 (numérique)

Découvrir la revue

Citer ce compte rendu

Larocque, A. (1975). Compte rendu de [The Naked Manager, by E. Dichter, Toronto, Macmillan of Canada, 1974, XII, 156 pp.] Relations industrielles /

Industrial Relations, 30(3), 553-553. https://doi.org/10.7202/028646ar

Tous droits réservés @ Département des relations industrielles de l'Université Laval, 1975
Ce document est protégé par la loi sur le droit d'auteur. L’utilisation des services d'Érudit (y compris la reproduction) est assujettie à sa politique d'utilisation que vous pouvez consulter en ligne.

https://apropos.erudit.org/fr/usagers/politique-dutilisation/ 
Il n'y a que les chapitres six ( $\left(0^{\circ}\right)$ et sept (7) qui présentent moins d'intérêt pour le lecteur canadien. Ces chapitres traitent des services et avantages sociaux publics et privés. On comprendra qu'ils reflètent la situation américaine, passablement différente de ce qu'on retrouve au Canada.

Mise à part cette réserve mineure, Motivation and Commitment est un ouvrage très valable. Beaucoup plus riche et dense que plusieurs des volumes traitant des mêmes sujets, c'est un condensé sérieux et de qualité. Il faut espérer que les autres volumes de cette série présenteront les mêmes qualités.

\section{Alcan - Arvida}

\section{Jean-Pierre BEAULIEU}

The Naked Manager, by E. Dichter, Toronto, Macmillan of Canada, 1974, XII, $156 \mathrm{pp}$.

Il est rarement donné de trouver des ouvrages en management qui ne fassent pas l'étalage de tout l'arsenal des techniques managériales. L'oeuvre de Dichter va au-delà de la technologie managériale, il place le gestionnaire face à lui-même, dépouillé de tous ses artifices. C'est un effort de réflexion et de discussion entre l'auteur et le lecteur pour retrouver la dimension humaine et le véritable sens de la gestion. En toute simplicité, sans les artifices de la terminologie usuelle, il trace les grandes lignes d'une philosophie de vie qui veut rompre avec l'image froide et asséchante que la tradition managériale a véhiculée.

Pour Dichter, c'est l'individu, le manager, qui est le centre du processus et ce n'est que dans la mesure où il se sent à l'aise qu'il est efficace. Aux techniques sophistiquées de gestion il oppose le gros bon sens et le goût du risque; à la planification minutieuse, il oppose l'acceptation d'un certain inconnu; à la démonstration froide et rigoureuse qui cherche à convaincre, il oppose le dialogue et la réflexion. Il cherche à enlever aux gestionnaires les illusions qu'ils enretiennent sur euxmêmes et tente de les amener à se voir tels qu'ils sont et de trouver satisfaction à adapter le milieu de travvail à leur style personnel plutôt que de se nier en se confondant avec leur environnement.
Ce petit livre s'adresse avant tout aux gestionnaires, cadres supérieurs et intermédiaires, qui sont dans le feu de l'action et qui se sentent accablés par leur activité quotidienne c'est-à-dire à presque tous... Carnegie avait fourni quelques «recettes» au débutant pour réussir en affaires, Dichter, lui, fournit idées et réflexions à celui qui est en place et qui administre pour qu'il se sente bien et heureux dans sa tâche. Sa démarche ne relève pas de l'expérimentation ni de la technique mais du «gros bon sens». Sa philosophie en est une essentiellement hédonistique.

L'ouvrage de Dichter m'apparaît susceptible d'aider plus d'un gestionnaire par la réflexion qu'il suscite. Il est de ces livres que l'on cherche à lire et relire. Le style est direct, le langage simple et surtout, pour les managers si pris par leur travail... le texte est court. Autant de raisons que l'on ne pourra servir comme excuses pour ne pas l'avoir lu!

Université Laval

Alain LAROCQUE

\section{Le travail dans l'entreprise et la so-} ciété modernes, (sous la direction de) Pierre Morin, Paris, C.E.P.L., 1974, $512 \mathrm{pp}$.

Cet ouvrage collectif sur le monde $\mathrm{du}$ travail peut être défini comme un dictionnaire encyclopédique. En effet, sa structure tient à la fois du dictionnaire et du traité, c'est-à-dire que, d'une part, on $y$ trouvera définis et classés alphabétiquement environ trois cents termes du domaine du travail (de même que plusieurs noms d'auteurs, tels Argyris, Taylor, Herzberg, Mayo, etc.), ainsi que dix articles-synthèse portant aussi bien sur des aspects importants du monde du travail (conditions de travail, relations professionnelles) que sur l'apport des différentes sciences de l'homme à l'étude du travail (sociologie, économie politique, philosophie). Les directeurs de la collection «Les sciences de l'action », dont fait partie ce volume, nomment «algo-livre » ce type d'ouvrage de référence.

L'éventail des termes définis est très varié; toutefois les références empiriques sont faites à la réalité francaise, ce qui limite la portée de l'instrument. Cependant, celui qui veut se familiariser rapidement avec le monde du travail français, pourra utiliser ce dic- 